\title{
PENGARUH SELF DIABETES MANAGEMENT EDUCATION (SDME) TERHADAP PENGETAHUAN ANGGOTA KELUARGA PENDERITA DIABETES MELITUS DI WILAYAH KERJA PUSKESMAS MANGASA KOTA MAKASSAR
}

The Effect Of Self Diabetes Management Education (SDME) For Knowledge Of Members Family Of Diabetes Mellitus Patients At Mangasa Public Health Centre Makassar

\author{
Sitti Rahmatia, Mardiana Mustafa, Andy Setiawan \\ Poltekkes Kemenkes Makassar \\ E-mail: ghaniandyy@gmail.com \\ No. Telp: 0853-4274-8473
}

\begin{abstract}
Self Diabetes Management Education (SDME) is a process of health education for individuals or families in managing Diabetes Mellitus which has been developed since the 1930s by Joslin Diabetes Center. SDME uses guideline, counselling and intervention methods to increase knowledge about Diabetes Mellitus and improve individual and family skills in managing Diabetes Mellitus. Lack of knowledge or public awareness is one of the factors that contribute to the high incidence of diabetes mellitus. In general, the purpose of the research was to determine the effect of SDME on the knowledge of family members with diabetes mellitus patients in the working area of the health centre in Mangasa, Makassar. This research used a quasi-experiment with pre posttest group design. The number of research samples was 17 respondents for the intervention group and 17 respondents in the control group. The intervention group received SDME for 3 weeks, while the control group was given Leaflet education. Based on the results of the Wilcoxon analysis, the value of $p=0.001$ is smaller than $0.05(<0.05)$, which means that there is a significant relationship between Self Diabetes Management Education and the knowledge of family members with Diabetes Mellitus. Self Diabetes Management Education Increases the knowledge of family members with Diabetes Mellitus patients at Mangasa Public Health Centre, Makassar.
\end{abstract}

Keyword: SDME, Knowledge, Diabetes Mellitus

\begin{abstract}
ABSTRAK
Self Diabetes Management Education (SDME) merupakan proses pendidikan kesehatan bagi individu atau keluarga dalam mengelola penyakit Diabetes Melitus yang telah dikembangkan sejak tahun 1930-an oleh Joslin Diabetes Center. SDME menggunakan metode pedoman, konseling dan intervensi untuk meningkatkan pengetahuan mengenai Diabetes serta meningkatkan keterampilan individu dan keluarga dalam mengelola penyakit Diabetes Melitus. Kurangnya pengetahuan atau kesadaran masyarakat menjadi salah satu faktor yang berkontribusi terhadap tingginya angka kejadian Diabetes Melitus. Secara umum tujuan penelitian untuk mengetahui pengaruh SDME terhadap pengetahuan anggota keluarga penderita Diabetes Melitus di Wilayah kerja Puskesmas Mangasa Kota Makassar. Penelitian ini menggunakan quasy experiment dengan pre post test group design. Jumlah sampel penelitian 17 responden untuk kelompok intervensi dan 17 responden kelompok kontrol. Kelompok intervensi mendapatkan SDME selama 3 minggu, sedangkan kelompok kontrol diberi edukasi berupa Leaflet. Berdasarkan hasil analisis Wilcoxon diperoleh nilai $p=0,001$ lebih kecil dari $0,05(<0,05)$ yang berarti ada hubungan yang signifikan antara Self Diabetes Management Education terhadap pengetahuan anggota keluarga penderita Diabetes Melitus. Self Diabetes Management Education meningkatkan pengetahuan anggota keluarga penderita Diabetes Melitus di Wilayah Kerja Puskesmas Mangasa Kota Makassar.
\end{abstract}

Kata Kunci: SDME, Pengetahuan, Diabetes Melitus

PENDAHULUAN

Self Diabetes Management Education (SDME) merupakan proses pendidikan kesehatan bagi individu atau keluarga dalam mengelola penyakit Diabetes Melitus yang telah dikembangkan sejak tahun 1930-an oleh Joslin Diabetes Center. SDME menggunakan metode pedoman, konseling dan intervensi untuk meningkatkan pengetahuan mengenai Diabetes dan meningkatkan keterampilan individu dan keluarga dalam mengelola penyakit Diabetes Melitus (Ridwan A, et. al., 2018).
Diabetes Melitus (DM) merupakan salah satu penyakit kronis yang saat ini semakin bertambah jumlah penderitanya. Di dunia prevalensi Diabetes setiap tahunnya semakin meningkat, pada tahun 2013 World health Organization (WHO) menunjukkan ada 382 juta orang yang menderita Diabetes, kemudian pada tahun 2014 meningkat menjadi 422 juta orang yang menderita Diabetes, dan pada tahun 2017 menjadi 425 juta penderita (IDF Diabetes Atlas, 2017).

Saat ini diperkirakan penderita Diabetes yang paling tinggi prevalensinya berada pada Negara bagian Western Pacific yang menyumbang 159 juta 
Vol. 10 No. 022019

e-issn : 2622-0148, p-issn : 2087-0035

penderita, dan diperkirakan akan menjadi 183 juta pada tahun 2045, diikuti oleh South-East Asia pada urutan kedua sebagai negara yang memiliki prevalensi Diabetes terbesar yaitu sebanyak 82 juta penderita dan diperkirakan akan menjadi 183 juta ditahun 2045, dan Benua Eropa menempati peringkat ketiga sebagai Negara dengan prevalensi Diabetes tertinggi yaitu sebesar 58 juta dan diperkirakan akan menjadi 67 juta pada tahun 2045 (IDF Diabetes Atlas, 2017).

International Diabetes Federation (IDF) pada tahun 2017 menyebutkan ada 4 juta kematian dengan prevalensi umur 20 - 79 tahun karena Diabetes, dan 3,2 juta diantaranya berasal dari Negara berkembang yang latar belakang tingkat ekonominya masih dalam tahap pertumbuhan. Sekitar $60 \%$ dari laki-laki \& $40 \%$ dari perempuan dengan Diabetes meninggal sebelum berusia 70 tahun di Wilayah Regional Asia Tenggara. Pada tahun 2015, Indonesia menempati peingkat ke-7 sebagai Negara dengan prevalensi penyandang Diabetes tertinggi dan prevalensi ini meningkat pada tahun 2017 menjadi 10,3 juta yang membuat Indonesia menempati nomor urut ke-6 sebagai Negara yang prevalensi Diabetesnya paling tinggi (WHO, 2016).

Laporan statistik dari Riset Kesehatan Dasar (Riskesdas) menunjukkan bahwa terjadi peningkatan prevalensi Diabetes di Indonesia dari $5,7 \%$ tahun 2007 menjadi $6,9 \%$ atau sekitar sekitar 9,1 juta pada tahun 2013. Seperti kondisi di dunia, Diabetes kini menjadi salah satu penyebab kematian terbesar di Indonesia.

Data yang dipublikasikan oleh Kemenkes, (2014) penyandang Diabetes di Sulawesi Selatan sebanyak 91.823 orang. Menurut hasil Riskesdas Tahun 2013 Prevalensi Diabetes yang didiagnosis dokter atau berdasarkan gejala sebesar $3,4 \%$. Prevalensi Diabetes yang didiagnosis dokter atau berdasarkan gejala, tertinggi di Kabupaten Tana Toraja 6,1\%, Kota Makassar 5,3\%, Kabupaten Luwu $5,2 \%$, dan Kabupaten Luwu Utara 4,0\% (Dinkes Prov. Sulsel, 2015). Kota Makassar merupakan salah satu daerah tertinggi jumlah penderita Diabetes di Wilayah Sulawesi Selatan, dengan data terakhir penderita Diabetes pada tahun 2016 sebanyak 4.555 orang (Dinkes Kota Makassar, 2016).

Dari survei data yang diperoleh di Puskesmas Mangasa Kota Makassar terdapat 52 penderita Diabetes yang tergabung dalam kelompok Program Pengelolaan Penyakit Kronis (Prolanis). Dan tercatat ada 102 kunjungan penderita Diabetes Melitus pada bulan Januari tahun 2019.

Kurangnya pengetahuan atau kesadaran masyarakat menjadi salah satu faktor yang berkontribusi terhadap tingginya angka kejadian Diabetes. Seseorang yang memiliki riwayat keturunan DM berisiko dua sampai dengan enam kali lipat terkena Diabetes jika melakukan pola hidup yang keliru, Keadaan ini cukup sering ditemukan di masyarakat Indonesia (Syamsiyah, 2017). Untuk itu perlu adanya pendidikan pengolahan atau dengan istilah SDME bagi mereka yang memiliki riwayat keturunan Diabetes untuk mencegah secara dini terjadinya Diabetes, yang mencakup pendidikan kesehatan (healht education), diet (pengaturan makanan), dan olahraga atau latihan fisik. Perlu untuk mempelajari cara untuk mengelola Diabetes dan mencegah atau menunda komplikasi (Beck J, et. al., 2017).

Salah satu kegiatan Pendidikan kesehatan yang penting diberikan kepada penderita Diabetes atau mereka yang beresiko terkena Diabetes untuk perubahan perilaku dan sebagai langkah awal dalam pencegahan dini terjadinya penyakit Diabetes yaitu SDME.

\section{METODE PENELITIAN}

Penelitian ini merupakan penelitian experimental dengan jenis quasy experimental dangan rancangan pre-test and post-test with control group design. Populasi dalam penelitian ini adalah anggota keluarga penderita Diabetes Melitus yang berada di Wilayah kerja Puskesmas Mangasa Kota Makassar. Jumlah sampel penelitian ini yaitu sebanyak 34 responden yang terbagi menjadi dua kelompok yaitu 17 responden kelompok intervensi dan 17 responden kelompok kontrol, sampel dalam penelitian ini diambil dari seluruh populasi yang ada di lokasi penelitian menggunakan teknik accidental sampling mengacu pada kriteria inklusi penelitian. Kriteria inklusi dalam penelitian ini yaitu sebagai berikut: 1). Orang yang memiliki riwayat keturunan Diabetes Melitus yang berada di Wilayah kerja Puskesmas Mangasa Kota Makassar. 2). Anggota keluarga kelompok Prolanis Penderita Diabetes Melitus yang belum menderita Diabetes. 3). Bersedia menjadi responden. 4). Mampu melakukan aktivitas sehari-hari secara mandiri. Instrumen penelitian yang digunakan oleh peneliti adalah berupa kuesioner DKQ-24 (Diabetes Knowledge Questionnaire). Kuesioner terdiri dari 24 pertanyaan mengenai pengetahuan responden terhadap Diabetes Melitus.

\section{HASIL PENELITIAN}

Tabel 1.

Data Demografi Responden di Wilayah Kerja Puskesmas Mangasa Kota Makassar Tahun 2019

\begin{tabular}{cccccc}
\multirow{2}{*}{ Kategori } & Karakteristik & \multicolumn{2}{c}{ Kel. } & \multicolumn{2}{c}{ Kel. } \\
& & $\mathrm{f}$ & $\%$ & $\mathrm{f}$ & $\%$ \\
\cline { 3 - 6 } & Remaja & 6 & 35,3 & 3 & 17,6 \\
\multirow{3}{*}{ Usia } & Dewasa & 8 & 47,1 & 9 & 52,9 \\
& Lansia & 3 & 17,6 & 5 & 29,4 \\
\hline Jenis & Laki-Laki & 8 & 47,1 & 6 & 35,3 \\
Kelamin & Perempuan & 9 & 52,9 & 11 & 64,7 \\
\hline
\end{tabular}


Vol. 10 No. 022019

e-issn : 2622-0148, p-issn : 2087-0035

\begin{tabular}{|c|c|c|c|c|c|}
\hline \multirow{3}{*}{ Pendidikan } & SMP & 2 & 11,8 & 2 & 11,8 \\
\hline & SMA & 10 & 58,8 & 12 & 70,6 \\
\hline & $\begin{array}{c}\text { Perguruan } \\
\text { Tinngi }\end{array}$ & 5 & 29,4 & 3 & 17,6 \\
\hline \multirow{3}{*}{ Pekerjaan } & Tidak Bekerja & 9 & 52,9 & 9 & 52,9 \\
\hline & PNS & 2 & 11,8 & 3 & 17,6 \\
\hline & $\begin{array}{c}\text { Pegawai } \\
\text { Swasta }\end{array}$ & 6 & 35,3 & 5 & 29,5 \\
\hline \multirow{2}{*}{$\begin{array}{c}\text { Status } \\
\text { Pernikahan }\end{array}$} & Menikah & 10 & 58,8 & 12 & 70,6 \\
\hline & $\begin{array}{c}\text { Belum } \\
\text { Menikah }\end{array}$ & 7 & 41,2 & 5 & 29,4 \\
\hline Riwayat & Bapak & 5 & 29,4 & 7 & 41,2 \\
\hline Keturunan & Ibu & 12 & 70,6 & 10 & 58,8 \\
\hline
\end{tabular}

Berdasarkan tabel 1. dapat diketahui bahwa anggota keluarga penderita DM di Wilayah Kerja Puskesmas Mangasa Kota Makassar pada kelompok intervensi rata-rata responden berusia dewasa sebanyak 8 orang $(47,1 \%)$, sedangkan responden yang berusai remaja sebanyak 6 orang $(35,3 \%$,), dan responden yang berusia lansia sebanyak 3 orang $(17,6 \%)$. Pada Kelompok kontrol rata-rata responden berusia dewasa sebanyak 9 orang $(52,9 \%)$, sedangkan responden yang berusia lansia sebanyak 5 orang $(29,4 \%)$. dan responden yang berusia remaja sebanyak 3 orang $(17,6 \%)$.

Pada kelompok intervensi sebagian besar berjenis kelamin perempuan sebanyak 9 orang $(52,9 \%)$, dan yang berjenis kelamin laki-laki sebanyak 8 orang $(47,1 \%)$. Pada kelompok kontrol sebagian besar berjenis kelamin perempuan sebanyak 11 orang $(64,7 \%)$, dan yang berjenis kelamin laki-laki sebanyak 6 orang $(35,3 \%)$.

Pada kelompok intervensi rata-rata tingkat pendidikan yaitu lulusan SMA sebanyak 10 orang (58,8\%), sedangkan lulusan Perguruan Tinggi sebanyak 5 orang $(29,4 \%)$, dan lulusan SMP sebanyak 2 orang $(11,8 \%)$. Pada kelompok kontrol rata-rata tingkat pendidikan yaitu lulusan SMA sebanyak 12 orang $(70,6 \%)$, sedangkan lulusan Perguruan Tinggi sebanyak 3 orang (17,6\%), dan lulusan SMP sebanyak 2 orang $(11,8 \%)$.

Pada kelompok intervensi rata-rata tidak bekerja yaitu sebanyak 9 orang (52,9\%), sedangkan yang bekerja sebagai Pegawai Swasta sebanyak 6 orang $(35,3 \%)$, dan yang bekerja sebagai PNS sebanyak 2 orang $(11,8 \%)$. Pada kelompok kontrol rata-rata tidak bekerja sebanyak 9 orang $(52,9 \%)$, sedangkan yang bekerja sebagai Pegawai Swasta sebanyak 5 orang $(29,5 \%)$, dan yang bekerja sebagai PNS 3 orang $(17,6 \%)$.

Pada kelompok intervensi rata-rata sudah menikah sebanyak 10 orang $(58,8 \%)$, dan yang belum menikah sebanyak 7 orang $(41,2 \%)$. Pada kelompok kontrol rata-rata sudah menikah sebanyak 12 orang $(70,6 \%)$, dan yang belum menikah $(29,4 \%)$.

Pada kelompok intervensi rata-rata yang membawa keturunan dari ibu sebanyak 12 orang $(70,6 \%)$, dan yang membawa keturunan dari bapak sebanyak 5 orang $(29,4 \%)$. Pada kelompok kontrol rata-tata yang membawa keturunan dari ibu

sebanyak 10 orang $(58,8 \%)$, dan yang membawa keturunan dari bapak sebanyak 7 orang $(41,2 \%)$.

Tabel 2.

Distribusi Frekuensi Responden Menurut Tingkat Pengetahuan Pre-test dan Post-test Kelompok Intervensi di Wilayah Kerja Puskesmas Mangasa Kota Makassar Tahun 2019

\begin{tabular}{cccc}
\hline \multirow{2}{*}{ Pengukuran } & \multicolumn{3}{c}{ Nilai } \\
\cline { 2 - 4 } & Mean & Min. & Max. \\
\hline Pre-test & 47,7947 & 25,00 & 79,17 \\
\hline Post-test & 77,4512 & 62,50 & 91,67 \\
\hline
\end{tabular}

Berdasarkan tabel 2. dapat di ketahui bahwa pada kelompok intervensi nilai rata-rata yang di dapat pada saat Pre-test yaitu 47,7947, sedangkan nilai yang di dapat paling rendah 25,00 , dan nilai yang di dapat paling tinggi yaitu 79,17 . Pada saat Post-test nilai rata-rata yang di dapat yaitu 77,4512 , sedangkan nilai yang di dapat paling rendah 62,50, dan nilai yang di dapat paling tinggi yaitu 91,67.

Tabel 3.

Distribusi Frekuensi Responden Menurut Tingkat

Pengetahuan Pre-test dan Post-test Kelompok

Kontrol di Wilayah Kerja Puskesmas Mangasa Kota Makassar Tahun 2019

\begin{tabular}{cccc}
\hline \multirow{2}{*}{ Pengukuran } & \multicolumn{3}{c}{ Nilai } \\
\cline { 2 - 4 } & Mean & Min. & Max. \\
\hline Pre-test & 42,6488 & 29,17 & 66,67 \\
\hline Post-test & 52,9424 & 37,50 & 79,17
\end{tabular}

Berdasarkan tabel 3. dapat di ketahui bahwa pada kelompok kontrol nilai rata-rata yang di dapat pada saat Pre-test yaitu 42,6488, sedangkan nilai yang di dapat paling rendah 29,17 , dan nilai yang di dapat paling tinggi yaitu 66,67. Pada saat Post-test nilai rata-rata yang di dapat yaitu 52,9424, sedangkan nilai yang di dapat paling rendah 37,50 , dan nilai yang di dapat paling tinggi yaitu 79,17.

Tabel 4.

Pengaruh Edukasi SDME Terhadap Pengetahuan Anggota Keluarga Penderita Diabetes Melitus di Wilayah Kerja Puskesmas Mangasa Kota Makassar Tahun 2019

\begin{tabular}{|c|c|c|c|c|}
\hline \multirow{3}{*}{ Test } & \multicolumn{2}{|c|}{ Pengetahuan } & \multirow{2}{*}{ Total } & \multirow{3}{*}{$p$} \\
\hline & Baik & Kurang & & \\
\hline & $f$ & $f$ & $f$ & \\
\hline $\begin{array}{c}\text { Pre-test } \\
\text { Intervensi }\end{array}$ & 6 & 11 & 17 & \multirow[b]{2}{*}{0,001} \\
\hline $\begin{array}{l}\text { Post-test } \\
\text { Intervensi }\end{array}$ & 17 & 0 & 17 & \\
\hline $\begin{array}{l}\text { Pre-test } \\
\text { Kontrol }\end{array}$ & 4 & 13 & 17 & \multirow{2}{*}{0,083} \\
\hline $\begin{array}{c}\text { Post-test } \\
\text { Kontrol }\end{array}$ & 7 & 10 & 17 & \\
\hline
\end{tabular}

Berdasarkan tabel 4. diperoleh hasil dari uji statistik (uji Wilcoxon) yang menunjukkan bahwa setelah dilakukan pengukuran pengetahuan Pre-test 
Vol. 10 No. 022019

e-issn : 2622-0148, p-issn : 2087-0035

dan Post-test edukasi SDME sebanyak 3 pertemuan pada kelompok intervensi di dapatkan nilai $b_{\text {value }}$ lebih kecil dari $0,05(b<0,05)$, maka $\mathrm{H}^{0}$ di tolak dan $\mathrm{H}^{\mathrm{a}} \mathrm{di}$ terima. Hal ini berarti pemberian edukasi SDME berpengaruh terhadap pengetahuan anggota keluarga penderita DM di Wilayah Kerja Puskesmas Mangasa Kota Makassar.

Pada kelompok kontrol di peroleh hasil setelah dilakukan pengukuran pengetahuan Pre-test dan Post-test perlakuan berupa pemberian media Leaflet

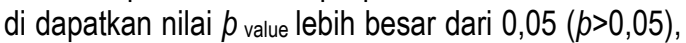
maka $\mathrm{H}^{\mathrm{a}}$ di tolak. Hal ini berarti pemberian media berupa Leaflet tidak berpengaruh terhadap pengetahuan anggota keluarga penderita DM di Wilayah Kerja Puskesmas Mangasa Kota Makassar.

\section{PEMBAHASAN}

Hasil penelitian menunjukkan bahwa dapat di ketahui pada kelompok intervensi nilai rata-rata yang di dapat pada saat Pre-test yaitu 47,7947, sedangkan pada saat Post-test nilai rata-rata yang di dapat yaitu 77,4512. Dan hasil penelitian pada kelompok kontrol nilai rata-rata yang di dapat pada saat Pre-test yaitu 42,6488 , sedangkan pada saat Post-test nilai ratarata yang di dapat yaitu 52,9424. Dari data tersebut dapat diketahui bahwa sebagian besar pengetahuan responden mengenai DM berada dalam kategori kurang sebelum dilakukan perlakuan dan setelah diberikan perlakuan mengalami peningkatan, hal ini dapat di lihat dari nilai rata-rata yang di hasilkan pada saat Per-test dan Post-test mengalami peningkatan nilai rata-rata. Pada kelompok intervensi mengalami peningkatan yang signifikan setelah diberikan perlakuan berupa edukasi SDME. Dan pada kelompok kontrol juga mengalami peningkatan pengetahuan namun tidak terlalu signifikan, hal ini disebabkan karena pada kelompok kontrol hanya diberikan media Leaftet saja tanpa ada konseling yang menyebabkan pertemuan edukasi dengan responden kurang efektif. Hal ini selaras dengan hasil penelitian yang di lakukan oleh Ridwan (2018) mengatakan bahwa adanya pengaruh SDME + SMS terhadap pengetahuan pasien mengenai diet pada penderita DM tipe II.

SDME dilakukan dengan menggunakan metode pedoman, konseling dan intervensi perilaku untuk meningkatkan pengetahuan mengenai Diabetes Melitus serta meningkatkan keterampilan individu dan keluarga dalam pengelolaan Diabetes Melitus secara mandiri (Nuari, 2017).

Pengetahuan merupakan hasil tahu, dan ini terjadi setelah orang melakukan pengindraan terhadap obyek tertentu. Sebagian besar pengetahuan manusia di peroleh melalui telinga dan mata, yaitu proses mendengar dan melihat. Pengetahuan merupakan domain yang penting dalam pembentukan tindakan seseorang (Notoatmodjo, 2003 dalam Lestari, 2015).

Menurut (Notoatmodjo, 2003 dalam Lestari, 2015) sebagian besar pengetahuan seseorang diperoleh melalui indra pendengaran yaitu telinga dan indra penglihatan yaitu mata. Pelaksanaan edukasi SDME melibatkan beberapa indera yaitu penglihatan dan pendengaran karena disampaikan melalui media Flipcart dan ceramah secara langsung. Peneliti beranggapan bahwa informasi yang disampaikan akan diingat oleh responden karena melibatkan beberapa panca indera.

Prinsip utama SDME menurut Funnell, et, al., (2008 dalam Nuari, 2017) adalah pendidikan DM efektif dalam memperbaiki hasil klinis dan kualitas hidup pasien meskipun dalam jangka pendek, SDME telah berkembang dari model pengajaran primer menjadi lebih toritis yang berdasarkan pada model pemberdayaan pasien, tidak ada program edukasi yang terbaik namun program edukasi yang menggabungkan strategi perilaku dan psikososial terbukti dapat memperbaiki hasil klinis, dukungan yang berkelanjutan merupakan aspek yang sangat penting untuk mempertahankan kemajuan yang di peroleh pasien selama program SDME.

Perubahan gaya hidup yang kecenderungannya semakin membaik pada penelitian ini di dikarenakan pendekatan yang dilakukan pada SDME menggunakan prinsip edukasi yang di berikan secara bertahap dan berkelanjutan, yang lebih menakan pada diskusi dan sharing, serta ada proses penguatan, motivasi dan penyadaran diri yang diberikan kepada individu itu sendiri. Proses SDME di lakukan selama 3 kali pertemuan, dengan kunjungan rumah telah menumbuhkan motivasi dan kesadaran responden karena melibatkan mereka secara langsung.

\section{SIMPULAN DAN SARAN}

Hasil Penelitian ini dapat simpulkan bahwa terdapat hubungan yang signifikan antara Self Diabetes Management Education (SDME) terhadap pengetahuan anggota keluarga penderita Diabetes Melitus di Wilayah Kerja Puskesmas Mangasa Kota Makassar.

Peneliti merekomendasikan agar SDME dapat digunakan sebagai salah satu program promosi kesehatan pada pelayanan kesehatan, materi pokok dalam pembelajaran, sumber informasi dan acuan bagi perawat, mahasiswa, institusi pelayanan kesehatan, dan peneliti lain yang ingin melakukan penelitian terkait edukasi DSME. 


\section{DAFTAR PUSTAKA}

Badan Pusat Statistik, P. S. (2015). Profil Kesehatan Prov. Sulawesi Selatan Tahun 2016. Dipetik Februari 24, 2019, dari https://dinkes.sulselprov.go.id/file/publik/data\%ProfilL\%202015.pdf

Beck, J., Greenwood, D., Blanton, L., et al. (2017). National Standards for Diabetes Self-Management Education and Support. Dipetik Februari $27, \quad 2019, \quad$ dari https://professional.diabetes.org/sites/professional.diabetes.org/files/media/2017 national_standards_for_d smes_public_comment.pdf

Bilous, R., \& Donelly, R. (2014). Buku Pegangan Diabetes Edisi Ke 4. Jakarta: Bumi Medika.

Dinas Kesehatan Kota Makassar. (2016). Profil Kesehatan Kota Makassar Tahun 2016.

Fatimah, R, N. (2015). Diabetes Melitus Tipe II. J Majority. Volume 4 Nomor 5. Dipetik Februari 27, 2019, dari http://juke.kedokteran.unila.ac.id/index.php/majority/article/viewFile/615/619

Haas L, Maryniuk M, Beck J, et al. (2012). National Standart for Diabetes Self Management Education and Support. Diabetes Care, Volume 35 page: 2393-2401.

Hendro. (2018). Hidup Sehat Pasca Diabetes - Based On True Story. Yogyakarta: Rapha Publishing.

IDF. (2017). Online Version Of DIABETES ATLAS Seventh Edition 2017. Dipetik Februari 24, 2019, dari http://diabetesasia.org/content/diabetes_quidelines/IDF_quidelines.pdf

Kemenkes, RI. (2013). Hasil Riset Kesehatan Dasar 2013. Jakarta: Badan Penelitian dan Pengembangan Kesehatan.

Kemenkes, RI. (2014). Profil Kesehatan Indonesia Tahun 2014. Jakarta : kementerian kesehatan Republik Indonesia.

Kemenkes, RI. (2016). Menkes: Mari Kita Cegah Diabetes Dengan Cerdik. Jakarta: Kementrian Kesehatan Republik Indonesia. Dipetik Februari 24, 2019, dari http://www.depkes.go.id/article/print/16040700002/menkes-marikita-cegah-diabetes-dengan-cerdik.html

Khotimah, K. (2014). Sehat dan Lezat Menu untuk Penderita Diabetes Mellitus. Yogyakarta: Rapha Publishing.

Kristanti. (2016). Pengaruh Self Diabetes Melitus (SDME) Terhadap Pengetahuan, Sikap, Kadar Gula Darah Prediabetes Di Puskesmas Pesantren I Kota Kediri. Tesis. Universitas Muhammadiah, Yogyakarta. Dipetik Februari 24, 2019, dari http://repository.umy.ac.id/handle/123456789/7532

Lestari, T. (2015). Kumpulan Teori Untuk Kajian Pustaka Penelitian Kesehatan. Yogyakarta: Nuha Medika.

Mutoharoh. (2017). Pengaruh Pendidikan Kesehatan Terhadap Tingkat Pengetahuan Tentang Penyakit Diabetes Melitus Pada Penderita Diabetes Melitus Tipe II Di Desa Ngadiwarno Sukorejo Kendal. Skripsi. Universitas Negeri Syarif Hidayatullah, Jakarta.

Notoatmodjo, S. (2015). Metodologi Penelitian Kesehatan. Jakarta: Rineka Cipta

Nuari, N. A. (2017). Strategi Manajemen Edukasi Pasien Diabetes Mellitus. Yogyakarta: Deepublish.

Nursalam. (2017). Metodologi Penelitian IImu Keperawatan Pendekatan Praktis. Jakarta: Salemba Medika.

Rahayu, E., Kamaluddin, R., \& Sumarwati, M. (2014). Pengaruh Program Diabetes Self Management Education Berbasis Keluarga Terhadap Kualitas Hidup Penderita Diabetes Melitus Tipe II Di Wilayah Puskesmas II Baturraden. The Soedirman Journal of Nursing. Volume 9, No. 3.

Ridwan, A., Barri, P., \& Nizami, N. (2018). Efektivita Diabetes Self Management Education Melalui SMS Terhadap Pengetahuan Penderita Diabetes Melitus. Idea Nursing Journal. Volume IX, No. 1. 
Siyoto, S. \& Sodik, A. M. (2015). Buku Dasar Metodologi Penelitian. Yogyakarta: Literasi Medika Publishing.

Soegondo, S., Suyono, S., Waspadji, S., Soewondo, P., Subekti, I., Semiardji, G., et, al. (2015). Penatalaksanaan Diabetes Melitus Terpadu Panduan Penatalaksanaan Diabetes Melitus Bagi Dokter Dan Edukator. Jakarta: Balai Penerbit FKUI.

Sugianto. (2016). Diabetes Melitus Dalam Kehamilan. Jakarta: Erlanga.

Syamsiyah, N. (2017). Berdamai Dengan Diabetes. Jakarta: Bumi Medika.

Tandra, H. (2017). Segala Sesuatu Yang Harus Anda Ketahui Tenang Diabetes Panduan Lengkap Mengenal Dan Mengatasi Diabetes Dengan Cepat Dan Mudah. Jakarta: PT. Gramedia Pustaka Utama.

WHO. (2016). Global Report On Diabetes. Dipetik Februari 24, 2018, dari http://apps.who.int/iris/bitstream/10665/204871/1/9789241565257_eng.pdf?ua=1

Wiastuti, S. M., Rondhianto, Widayati, N. (2017). Pengaruh Diabetes Self Management Education and Support (DSME/S) Terhadap Stres Pada Pasien Diabetes Melitus (DM) Tipe II Di Wilayah Kerja Puskesmas Patrang Kabupaten Jember. e-Jurnal Pustaka Kesehatan. Volume 5, No. 2.

Yuanita, A., Wantiyah, \& Susanto, T. (2014). Pengaruh Diabetes Self Management Education (SDME) Terhadap Resiko Terjadinya Ulkus Diabetik Pada Pasien Rawat Jalan Dengan Diabetes Melitus (DM) Tipe II Di RSD dr. Soebandi Hospital Jember. e-Jurnal Pustaka Kesehatan. Volume 2, No. 1. 